\title{
Arabidopsis and rice showed a distinct pattern in ZIPs genes expression profile in response to $\mathrm{Cd}$ stress
}

\author{
Xin Zheng ${ }^{1}$, Liang Chen ${ }^{1}$ and Xiaofang $\mathrm{Li}^{1,2^{*}}$ (]
}

\begin{abstract}
Background: Plant ZIP genes represent an important transporter family involved in metal transport. Evidence has implied that some ZIPs may contribute to plant Cd uptake, but a genome-wide examination of ZIPs' role in Cd tolerance and uptake has rarely been reported. In this study, a genome-wide bioinformatic screening of candidate ZIP genes in Arabidopsis and rice was performed, followed by a systematic determination of their expression profile in response to $\mathrm{Cd}$ stress. Typical up-regulated ZIPs genes were then expressed in yeast cells to examine their effect on hosts' Cd uptake.

Results: A total of 27 ZIP genes in Arabidopsis and rice were screened out based on sequence similarity. In Arabidopsis, Cd exposure strongly impacted the expression of most ZIPs, among which AtIRT1, AtIRT2, AtIRT4 AtZIP9, AtZIP10 and AtZIP12 were sharply up-regulated and AtIRT3, AtIRT5 were significantly down-regulated in root. In rice, all tested genes in shoot except for OsIRT1 and OsIRT12 were sharply up-regulated, while OsIRT1 and OsZIP1 in root were significantly down-regulated. Interestingly, some genes like AtIRT3, AtZIP5, AtZIP12, OsIRT1 and OsZIP1 showed converse expression regulation when subject to the tested Cd stress. When expressed in yeast cells, three ZIPs, AtIRT1, OsZIP1 and OsZIP3, caused a substantial increase in Cd sensitivity and Cd accumulation of the host cells.

Conclusions: In conclusion, this study revealed a distinct pattern in ZIPs family genes expression between Arabidopsis and rice in response to $\mathrm{Cd}$ stress. Arabidopsis mainly up-regulated root ZIPs genes, while rice mainly up-regulated shoot ZIPs genes. Three genes, AtIRT1, OsZIP1 and OsZIP3, conferred an increased Cd accumulation and sensitivity to $\mathrm{Cd}$ stress when expressed in yeast cells, further implying their roles in $\mathrm{Cd}$ uptake in plants.
\end{abstract}

Keywords: ZIP family, Cd, Metal cation transporter, Gene expression, Cd uptake

\section{Background}

The zinc(Zn)-regulated/iron(Fe)-regulated transporterlike family proteins (ZIPs) are membrane-located proteins for cations transport (Eng et al. 1998; Guerinot 2000). They have been found to exist broadly in prokaryotic cells, fungi, plants and mammalians. In plants, ZIPs have been identified in both dicots and monocots, such as Arabidopsis (Grotz et al. 1998; Milner et al. 2013),

\footnotetext{
*Correspondence: xfli@sjziam.ac.cn; x.li10@uq.edu.au

${ }^{1}$ Key Laboratory for Agricultural Water Resources, Center for Agricultural

Resources Research, Institute of Genetics and Developmental Biology,

Chinese Academy of Sciences, Shijiazhuang 050021, Hebei, People's

Republic of China

Full list of author information is available at the end of the article
}

rice (Chen et al. 2008), maize (Li et al. 2013), medicago (Lopez-Millan et al. 2004; Stephens et al. 2011) and barely (Tiong et al. 2015). Grotz et al. identified five ZIP genes (IRT1, ZIP1-4) in Arabidopsis (Grotz et al. 1998), and later up to 11 ZIP genes from Arabidopsis were detected bioinformatically (Guerinot 2000). Roles of ZIP1-12 from Arabidopsis in $\mathrm{Zn}$ transport were explored experimentally (Milner et al. 2013). More recently, 18 ZIPs from Arabidopsis and 16 ZIPs from rice were annotated (Ivanov and Bauer 2017).

In Arabidopsis and rice, only a small number of ZIPs have been examined for biological functions in plant till now. Arabidopsis IRT1 is a well-studied ZIP gene first identified as a crucial transporter for plant Fe uptake 
(Varotto et al. 2002; Vert et al. 2002). Arabidopsis IRT1 can be induced by iron deficiency (Korshunova et al. 1999; Connolly et al. 2002), and may play a role in $\mathrm{Mn} /$ $\mathrm{Zn}$ transport as well (Korshunova et al. 1999; Rogers et al. 2000; Connolly et al. 2002). Biological functions in $\mathrm{Zn} /$ Fe transport of AtIRT2 (Vert et al. 2001, 2009), AtZIP1/2 (Grotz et al. 1998; Wintz et al. 2003; Milner et al. 2013), OsIRT1 (Nakanishi et al. 2006; Lee and An 2009; Ishimaru et al. 2006; Bughio et al. 2002) and OsZIP4/5/8 (Ishimaru et al. 2005; Chen et al. 2008; Lee et al. 2010a, b; Yang et al. 2009) have also been examined in the past decade.

A few studies have also implied that ZIPs may be involved in Cd transport. Yeast cells expressing AtIRT1 showed increased Cd sensitivity (Rogers et al. 2000; Vert et al. 2001), and IRT1-dependent $\mathrm{Fe} / \mathrm{Mn} / \mathrm{Zn}$ uptake was inhibited by excess Cd (Eide et al. 1996; Korshunova et al. 1999). The Arabidopsis IRT1 knock-out mutant irt1-1 exhibited reduced $\mathrm{Cd}$ sensitivity and $\mathrm{Cd}$ accumulation (Vert et al. 2002; Fan et al. 2014), while overexpression of AtIRT1 increased Cd sensitivity in Arabidopsis (Connolly et al. 2002). AtIRT2, phylogenetically similar to AtIRT1, increased Cd uptake when overexpressed in Arabidopsis (Vert et al. 2009), though the yeast cells expressing AtIRT2 exhibited no altered Cd sensitivity (Vert et al. 2001). In rice, expression of OsIRT1 and OsIRT2 made the cells more sensitive to $\mathrm{Cd}$ and increased $\mathrm{Cd}$ accumulation (Nakanishi et al. 2006; Lee and An 2009). Nonetheless, we still know little about the roles of most of the ZIPs genes in Cd stress response in Arabidopsis and rice.

In this study, genome-wide ZIPs identification in Arabidopsis and rice was performed with rigorous evolutional analysis. A comparative examination of genomewide expression profile of ZIPs in Arabidopsis and rice in response to $\mathrm{Cd}$ stress were carried out. Their role in $\mathrm{Cd}$ uptake of typical ZIPs responding to $\mathrm{Cd}$ stress was further tested by expressing them in yeast. As expected, most identified ZIPs gene expression responded remarkably to Cd stress, while unexpectedly it was found that Arabidopsis and rice showed a distinct pattern in ZIPs genes expression profile. These results may help to elucidate the plants' genetic basis for $\mathrm{Cd}$ translocation via a ZIPs-dependent pathway.

\section{Materials and methods \\ Bioinformatics}

Genomic query of Arabidopsis and rice ZIP family genes was performed online using the PLAZA database (http:// bioinformatics.psb.ugent.be/plaza/). The sequences of 27 ZIP genes were retrieved manually from the TAIR database (http://www.arabidopsis.org/index.jsp) and the TIGR database (http://rice.plantbiology.msu.edu/index .shtml).
TM regions and other domains of the identified ZIPs gens were predicted through the TMHMM Server (http://www.cbs.dtu.dk/services/TMHMM-2.0/) and UniProtKB database (http://www.uniprot.org/), following a routine procedure.

\section{Experimental design}

Arabidopsis thaliana ecotype Col-0 and Oryza sativa ssp. japonica ( $c v$. Taichung65) were subject to $\mathrm{Cd}$ inhibition test. For Arabidopsis, plants were germinated on Murashige and Skoog (MS; pH 5.7) solid medium containing $1 \%(\mathrm{w} / \mathrm{v})$ sucrose. A total of 601 -week-old seedlings were transferred to MS (control) or MS with $300 \mu \mathrm{M} \mathrm{CdCl}_{2}$ (Cd stress treatment) solid medium, and grown for 3 days in a controlled chamber environment under a $16 / 8 \mathrm{~h}$ photoperiod at $22^{\circ} \mathrm{C}$. For rice, seedlings were germinated hydroponically in distilled water. A total of six 10-day-old seedlings were then subject to a hydroponic culture in distilled water (control) or $300 \mu \mathrm{M} \mathrm{CdCl}_{2}$ solution (Cd stress treatment) for 3 days under $16 / 8 \mathrm{~h}$ photoperiod at $25^{\circ} \mathrm{C}$. The $\mathrm{Cd}$ concentration used in this study was selected based on our pilot experiment.

After Cd stress treatment, the shoot and root tissues were harvested and frozen immediately in liquid nitrogen. Total RNA was isolated from the tissues using Trizol reagent (Invitrogen, Corp., Carlsbad, CA, USA) and treated with DNase I (Promega, Madison, WI, USA). A total of $5 \mu \mathrm{g}$ RNA was used for reverse transcription with PrimeScript ${ }^{\mathrm{TM}} \mathrm{RT}$ reagent Kit (Takara Biotechnology Co. Ltd., Dalian, China) following the manufacturer's protocol.

Quantitative Real-Time PCR (qPCR) was performed in a Bio-Rad CFX Connect ${ }^{\mathrm{TM}}$ Real-Time PCR Detection System (Hercules, CA, USA) using a SYBR Green Premix Ex Taq (Takara). The PCR parameters were set as: $95{ }^{\circ} \mathrm{C}$ for $5 \mathrm{~min}$, followed by 40 cycles of $95{ }^{\circ} \mathrm{C}$ for $10 \mathrm{~s}$ and $60{ }^{\circ} \mathrm{C}$ for $30 \mathrm{~s}$. Arabidopsis ACTIN gene (GenBank accession number NM_179953) and rice ACTIN gene (GenBank accession number XM_015774830) were used as internal references. Relative gene expression levels were detected using the $2^{-\Delta \Delta C T}$ method (Livak and Schmittgen 2001). Gene expression level was normalized using shoot expression level of each gene in the controls as a calibrator. All primer sequences are listed in the Additional file 1: Table S1.

$\mathrm{Cd}$ sensitivity analysis was performed using drop assay. Full-length coding sequence (CDS) was obtained via PCR amplification (see primers in Additional file 1: Table S2), and ligated into pCEV-G1-Km vector under the PGK1 promoter. The recombinant plasmids were then introduced into Saccharomyces cerevisiae (strain AH109) using a lithium acetate-based method. Transformed cells were cultured in Yeast Extract Peptone Dextrose (YPD) 
media with $300 \mu \mathrm{g} / \mathrm{mL}$ geneticin (G418), harvested by centrifugation, and resuspended in water $\left(\mathrm{OD}_{600}=1.0\right)$, followed by a serial dilution. A total of $5 \mu \mathrm{L}$ of each dilution was inoculated onto the YPD plates containing $300 \mu \mathrm{g} / \mathrm{mL}$ G418 and $50 \mu \mathrm{M} \mathrm{CdCl}_{2}$. Cells harbouring empty pCEV-G1-Km were used as a negative control. The plates were incubated at $28{ }^{\circ} \mathrm{C}$ for 5 days and the growth of the colonies was subsequently observed.

For the determination of $\mathrm{Cd}$ concentration in transformed yeast cells, cells expressing ZIPs were harvested after $12 \mathrm{~h}$ with $50 \mu \mathrm{M} \mathrm{CdCl}{ }_{2}$ treatment. Cd was determined using a flame atomic absorption spectrometry (F-AAS) quantitative method. In Brief, cells in the liquid culture were harvested by centrifugation at $4000 \times g$ and washed three times with $3 \% \mathrm{NaCl}$ solution. The cells were then oven-dried, weighed and digested using $4 \mathrm{~mL}$ $65 \% \mathrm{HNO}_{3}$. The digested mixture was dissolved in $3 \mathrm{~mL}$ Millipore ${ }^{\circledR}$ water and subject to Cd determination using a Zeenit 700 P Atomic Absorption Spectrometer (Analytik Jena, Germany) equipped with a flame atomizer. CRM Laver (GWB10023, certified by IGGE) was used as a standard reference material for $\mathrm{Cd}$ determination.

\section{Data analysis}

Phylogenetic analysis was performed using MEGA 7 (Kumar et al. 2016). The model of ZIP gene structure was constructed using Gene Structure Display Server (http:// gsds.cbi.pku.edu.cn/).

Statistical analysis was performed using SPSS 21.0 (IBM, New York, USA). Unpaired two-tailed t test was performed for comparison between the controls and the $\mathrm{Cd}$ stress group.

\section{Results and discussion}

In this study, 15 candidate ZIP genes from Arabidopsis and 12 from rice were screened out based on sequence similarity. The number of ZIPs identified here was similar to previous studies (Ivanov and Bauer 2017; Guerinot 2000). Evolutionary analysis further indicated that all of these ZIP genes contain 1-3 introns (Additional file 1: Figures S1 and S2), whose protein precursors comprise eight TM regions ( 20 aa length), one variable region with a conserved HG repeat and a typical signal peptide (SP) located on the N-terminal (Fig. 1). AtZIP13 and OsZIP13, which were previously annotated as putative $\mathrm{Zn}$ transporter (Ivanov and Bauer 2017), contain more TM domains. AtZTP29, AtIAR1, OsIAR1, OsZIP11 and OsZIP12 contain more than 10 exons. These ZIP-like genes seem to be phylogenetically distant from SpZRT1 and AtIRT1 and were not tested in this study. Phylogenetic clustering of the tested 27 ZIPs identified three subgroups, which is similar to previous study (Ivanov and
Bauer 2017), namely the seed plant-specific group, the mixed plant group, and the mixed group1/2 (Fig. 1).

Most previous studies on ZIPs' biological functions focused on $\mathrm{Zn} / \mathrm{Fe} / \mathrm{Mn} / \mathrm{Cu}$ uptake in yeast cells (Table 1 ), and expression profile of most ZIPs (except for AtIRT1/2 and $O s I R T 1 / 2$ ) in response to $\mathrm{Cd}$ remained unknown. In this study, the genome-wide expression profile of ZIP genes in response to $\mathrm{Cd}$ stress in Arabidopsis and rice were quantified using qPCR. To induce a substantial stress response, $300 \mu \mathrm{M} \mathrm{Cd}$ in culture medium was applied based on our pilot experiment. The 3 days' treatment obviously inhibited seedling growth and root elongation of both Arabidopsis and rice, and rice seedling height was also reduced (Fig. 2a). It was reported that even moderate $\mathrm{Cd}$ exposure can cause toxic symptoms and increased Cd accumulation in Arabidopsis (Fan et al. 2014) and rice (Rafiq et al. 2014). The Cd level used here significantly reduced the root length and seedling dry weight (Additional file 1: Figure S3), and was thus supposed to induce rapid expressional changes in the tested plants.

In Arabidopsis, Cd exposure impacted the expression of all ZIPs significantly. Strikingly, AtIRT1 was induced with a 525-fold increase in shoot and a 22-fold increase in root (Fig. 2b). As abovementioned, some evidence already pointed to the Cd transport role of AtIRT1 in yeast cells (Korshunova et al. 1999; Rogers et al. 2000; Vert et al. 2001; Eide et al. 1996) and in Arabidopsis (Fan et al. 2014; Connolly et al. 2002; Vert et al. 2002). Considering that AtIRT1 is mainly expressed in root (Vert et al. 2002), AtIRT1 may function as a pump absorbing $\mathrm{Cd}$ from soil into root under sever Cd stress. A sharp increase of AtIRT1 expression in shoot was also observed, indicating its potential role in $\mathrm{Cd}$ transport in shoot. Indeed, overexpression of AtIRT1 in yeast increased the hosts' sensitivity substantially (Fig. 3). Cd accumulation of yeast cells expressing AtIRT1 was also increased by $40.1 \%$, compared with the control (Additional file 1: Figure S4). Taken together, the results here further confirmed the role of AtIRT1 in plant Cd uptake implied in previous studies (Rogers et al. 2000).

Like AtIRT1, AtIRT2 was induced with a 1452-fold increase in shoot and a fourfold increase in root (Fig. 2b). Previous studies showed that AtIRT2 overexpression increased Cd uptake of transgenic Arabidopsis, probably through the induction of AtIRT1 expression (Vert et al. 2001, 2009). In this study, while both AtIRT2 and AtIRT1 were coincidently sharply induced when subject to Cd stress, overexpression of AtIRT2 caused no significant changes in neither $\mathrm{Cd}$ sensitivity nor $\mathrm{Cd}$ accumulation (Fig. 3 and Additional file 1: Figure S4). It is thus very likely that AtIRT2 worked indirectly and synergistically with AtIRT1 in response to the Cd stress. 

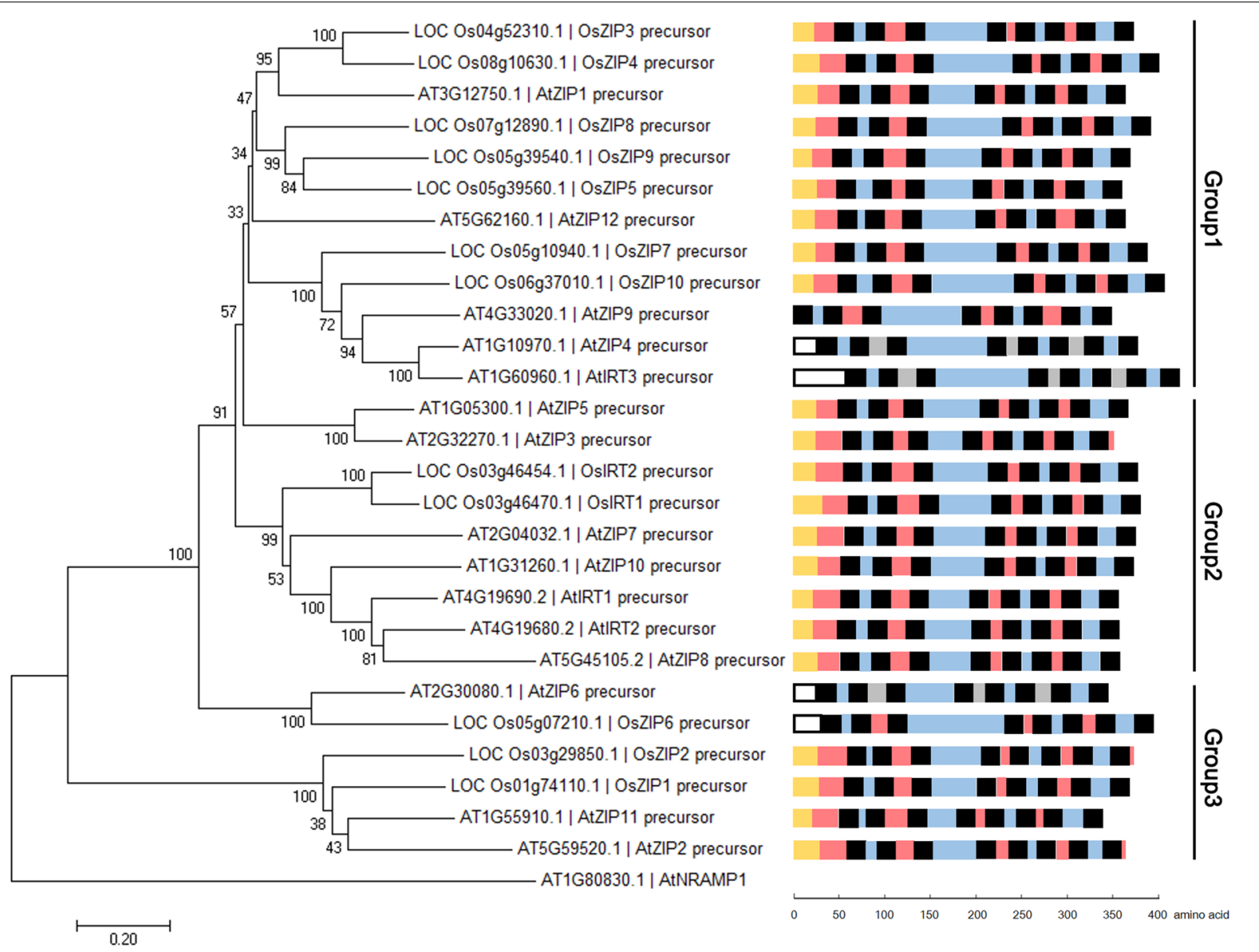

Fig. 1 Phylogenetic relationship of identified ZIPs in Arabidopsis and rice. The Neighbor-Joining tree was generated using MEGA7 with 1000 bootstrap replicates, and rooted to the AtNRAMP1. Topological structure was predicted using UniProtKB and TMHMM. Black boxes indicate TM regions. Pink boxes indicate extracellular regions. Blue boxes represent cytoplasmic regions. Gray boxes represent luminal regions. Yellow boxes represent SP region. Uncharacteristic SPs are represented by the white boxes

It was also highlighted that the expression of AtZIP9 was significantly increased by ninefolds in shoot and 57-folds in root after Cd stress (Fig. 2b). Till now no evidence showed any role of AtZIP9 in Cd uptake. The strong induction by $\mathrm{Cd}$ stress may imply its role in $\mathrm{Cd}$ transport, and its overexpression in yeast cells moderately increased hosts' sensitivity to Cd. Conversely, expression of AtZIP9 did not increase the Cd accumulation of host cells (Additional file 1: Figure S4). As a hypothetic transmembrane ion transporter, AtZIP9 might affect the growth of host cells by a Cd-independent way. In addition, AtIRT3, AtZIP4, AtZIP5, AtZIP11 and AtZIP12 showed converse expression regulation when subject to the tested Cd stress, and AtZIP7 was reduced in shoot and was under the detection limit in root (Fig. 2b). Their potential roles in Cd transport merit a further investigation.
In rice, homologous ZIPs responded differently from Arabidopsis to the Cd stress. Unlike in Arabidopsis, $\mathrm{Cd}$ stress increased the expression of most rice ZIPs in shoot but not root. These results imply that all these $\mathrm{Cd}$-induced ZIPs involve in plant response to $\mathrm{Cd}$. Except for OsIRT2, all ZIPs were significantly induced in rice shoot (Fig. 2b). Like AtIRT3, expression changes of OsIRT1 and OsZIP1 were converse in shoot and root (Fig. 2b). The positive role of OsIRT1 and OsZIP1 was demonstrated in the response of yeast and/or plant to Cd stress (Nakanishi et al. 2006; Lee and An 2009; Ramesh et al. 2003). Rice over-expressing OsIRT1 showed reduced plant height and increased $\mathrm{Cd}$ accumulation under $300 \mu \mathrm{M}$ Cd stress (Lee and An 2009), and the growth of OsZIP1-expressing yeast cells was inhibited by $10 \mu \mathrm{M} \mathrm{Cd}$ stress. In this study, the expression regulation of OsIRT1 and OsZIP1 in response to $\mathrm{Cd}$ stress was contrary between root and shoot. 


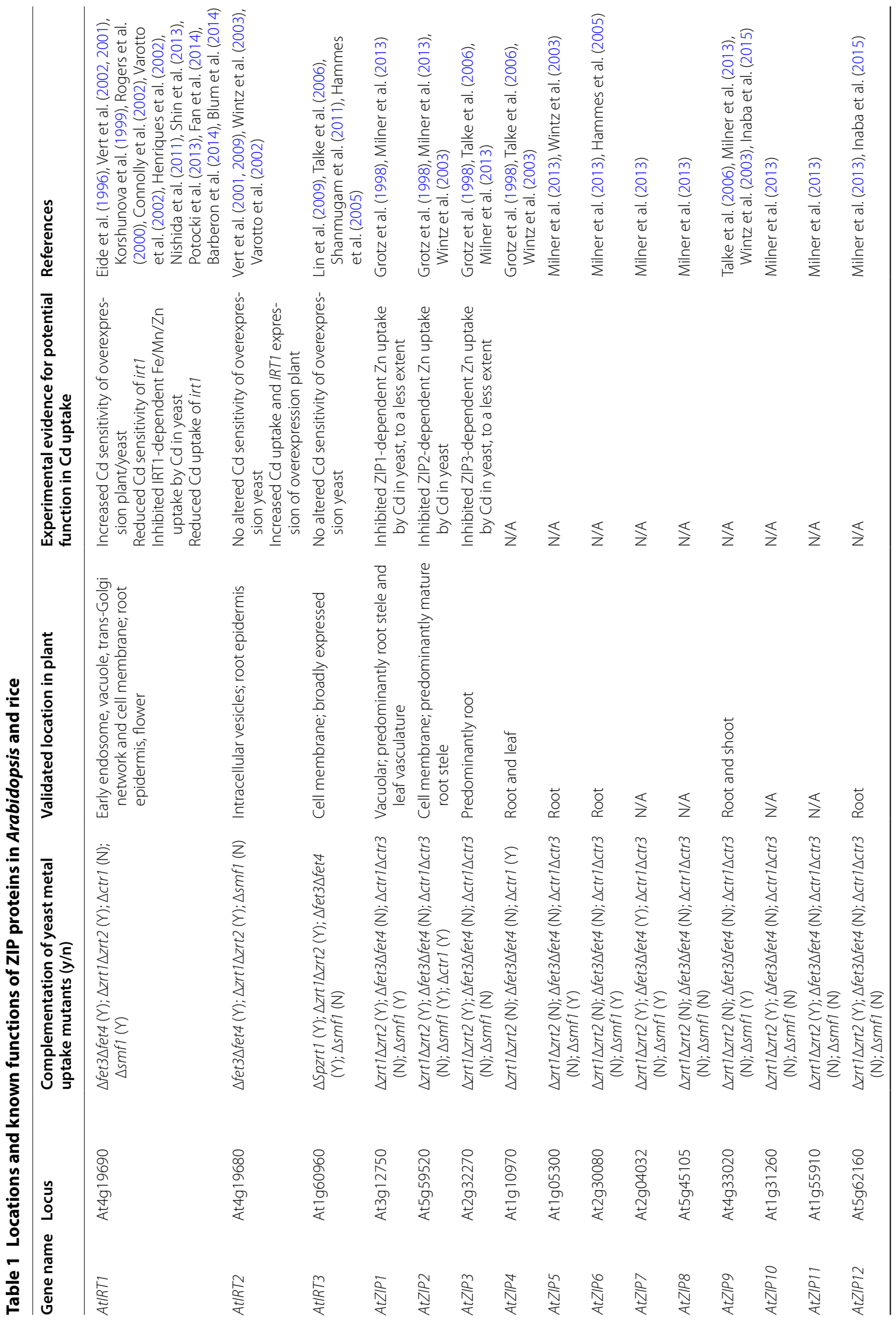




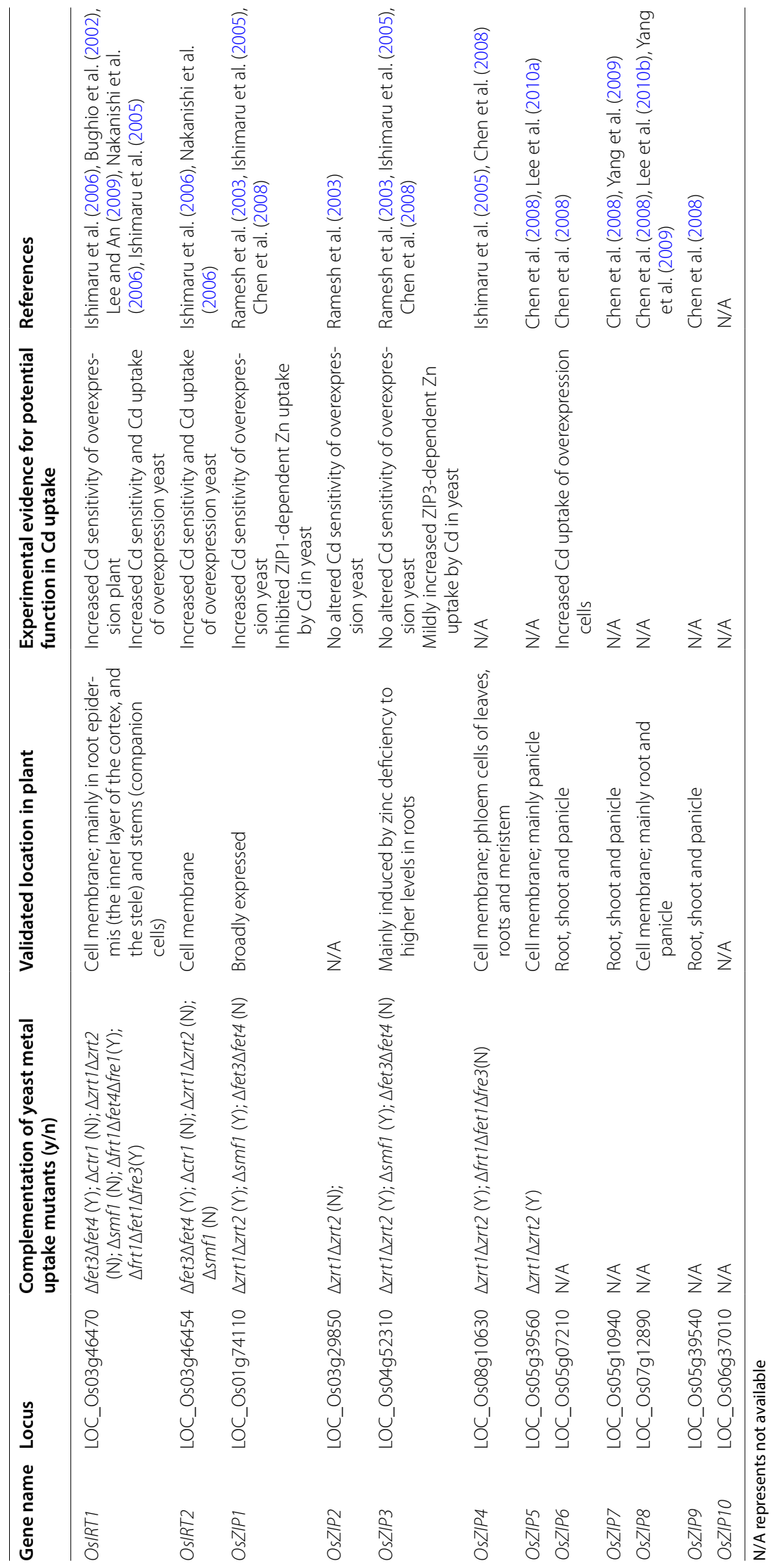


a

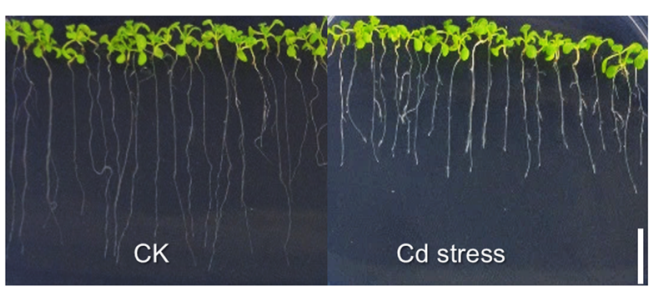

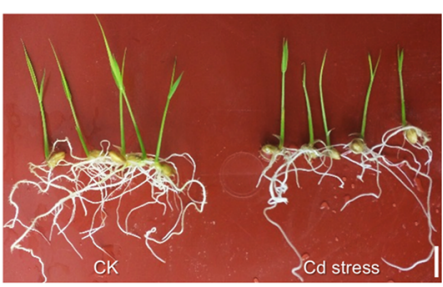

b

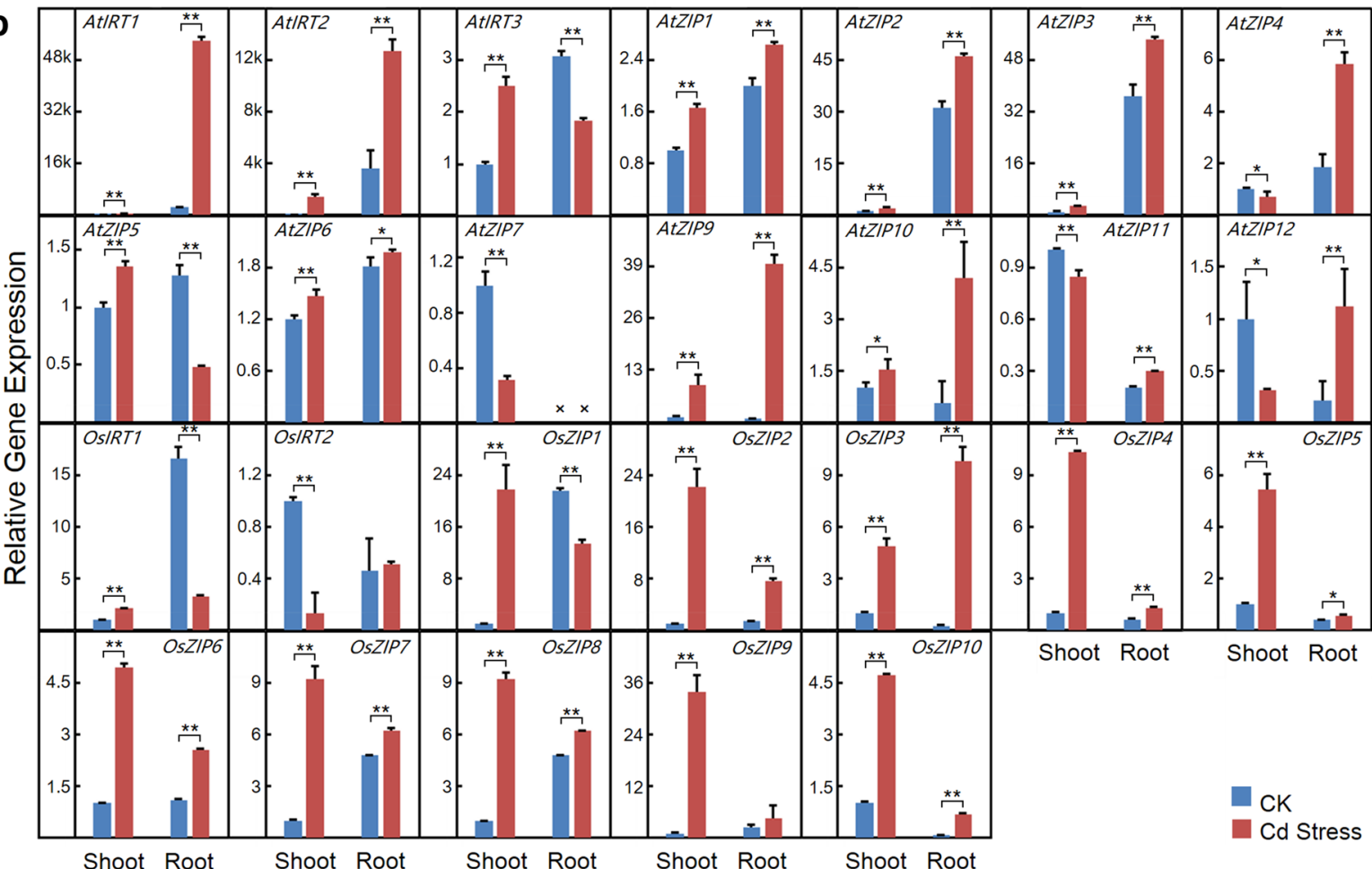

Fig. 2 Expression profiles of ZIP genes of Arabidopsis and rice in response to Cd stress. a 1-week-old and 10-day-old seedlings of Arabidopsis and rice were treated with $300 \mu \mathrm{M} \mathrm{CdCl}_{2}$ for 3 days. Scale bars indicate $1 \mathrm{~cm}$. $\mathbf{b}$ Changes in the expression of the 26 ZIP genes in response to Cd exposure Gene expression level was normalized using shoot expression level of each gene in the controls as the calibrator. ( $n=3$, Student $t$ test, *indicates $\mathrm{P}<0.05$, **indicates $\mathrm{P}<0.01$ )

Rice might have a feedback regulation of OsIRT1 and OsZIP1 in root to prevent increasing Cd uptake from soil.

OsZIP1-10 were subject to $\mathrm{Cd}$ sensitivity and $\mathrm{Cd}$ accumulation tests. The expression of OsZIP1 and OsZIP3 in yeast caused an increased Cd sensitivity and $\mathrm{Cd}$ accumulation (Fig. 3 and Additional file 1: Figure S4), suggesting their potential roles in Cd uptake. This result is different from those by Ramesh et al. (2003), where yeast ZHY3 strains were used and different culture medium was applied. It was also noticed that OsZIP6 did not caused an obvious increasing in $\mathrm{Cd}$ sensitivity (Fig. 3). This is not consistence with previous report, in which Xenopus laevis oocytes was used to test the Cd sensitivity (Kavitha et al. 2015). Different host and micro-environment may cause the altered conformation and activity of tested proteins. Expression of OsZIP5-10 failed to alter Cd sensitivity and $\mathrm{Cd}$ accumulation of host cells obviously, implying that these ZIPs probably did not uptake $\mathrm{Cd}$ individually. Considering that AtIRT2 involves in indirect Cd uptake in Arabidopsis, these Cd-induced ZIPs may also play roles in Cd uptake or transport indirectly. Their potential roles under $\mathrm{Cd}$ stress need further investigation using transgenic plants.

Indeed, this study showed that many ZIPs were significantly induced by $\mathrm{Cd}$ stress even the growth of seedling was inhibited obviously, and some of them increased hosts' $\mathrm{Cd}$ sensitivity or $\mathrm{Cd}$ accumulation. These results will help to elucidate the genetic basis 


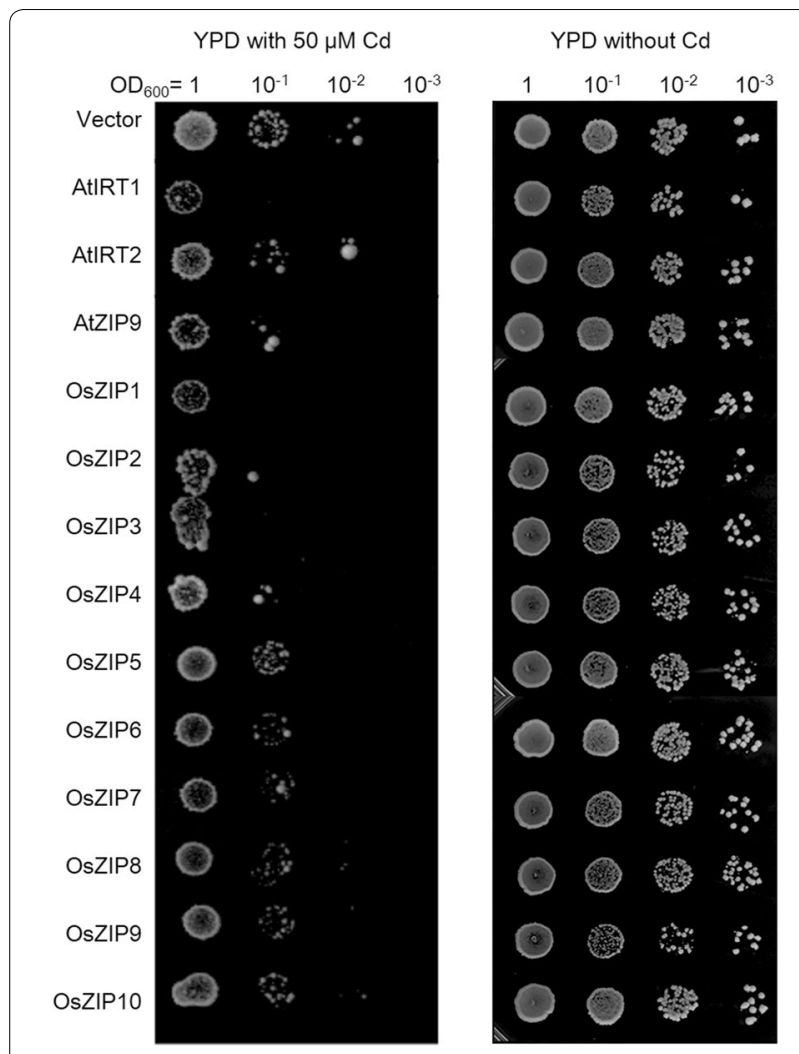

Fig. 3 Drop assay for Cd sensitivity of yeast cells (S. cerevisiae AH109) expressing representative ZIPs tested in this study. The transformed cells expression ZIPs were subjected to a serial dilution $\left(0-10^{-4}\right)$ drop assay on YPD plates. $300 \mu \mathrm{g} / \mathrm{mL}$ G418 was added to maintain the vectors. Plates containing $50 \mu \mathrm{M} \mathrm{CdCl}$, were incubated at $28^{\circ} \mathrm{C}$ for 5 days and growth state was subsequently observed. This experiment was performed three times

for Cd accumulation via a ZIP-dependent pathway in plants. Further analysis using transgenic plants will clarify the biological function of these ZIPs in plant $\mathrm{Cd}$ uptake and transport.

\section{Conclusions}

In conclusion, this study revealed a distinct pattern in ZIPs genes expression regulation in response to $\mathrm{Cd}$ stress between Arabidopsis and rice. Arabidopsis mainly up-regulated root ZIPs genes, while rice mainly upregulated shoot ZIPs genes. Interestingly, some genes like AtIRT3, AtZIP5, AtZIP12, OsIRT1 and OsZIP1 showed contrary expression regulation when subject to the tested Cd stress. Three genes, AtIRT1, OsZIP1 and OsZIP3, conferred an increased sensitivity to Cd stress and more $\mathrm{Cd}$ accumulation when expressed in yeast cells, implying a role in direct $\mathrm{Cd}$ uptake in plants.

\section{Additional file}

Additional file 1: Table S1. The qPCR primers used in this study. Table S2. Primers used in plasmid construction. Figure S1. Genome locations of 27 ZIP genes in Arabidopsis (A) and rice (B). Information were acquired in the PLAZA database and plotted using Photoshop CS6. Figure S2. Evolutionary relationships of ZIP family genes and their structures. The Neighbor-Joining tree was produced using MEGA7 with 1,000 bootstrap replicates, and the gene structures was predicted using Gene Structure Display Server. Dark blue boxes indicate exons; black lines indicate introns; light blue boxes indicate untranslated regions. Figure S3. Effect of Cd stress on root length ( $A$ and $B$ ) and dry weight ( $C$ and $D)$ of Arabidopsis and rice. (for root length, $n=20$; for dry weight, $n=3$. Student $t$ test, * indicates $P<0.05)$. Figure S4. Effect of ZIPS on Cd accumulation. Cells expressing ZIPs were incubated using liquid YPD medium plus 300 mg/ $\mathrm{mL} \mathrm{G418}$ and $50 \mu \mathrm{M}$ Cd for $12 \mathrm{~h}$, after which the Cd concentration of each strain was measured by an atomic absorption spectrometer method. Cells harboring empty pCEV-G1-Km (Vector) was used as a negative control. $\left(n=3\right.$, student $t$ test, $\left.{ }^{*} P<0.05\right)$.

\section{Abbreviations}

ZIPs: zinc(Zn)-regulated/iron(Fe)-regulated transporter-like family proteins; Cd: cadmium; TM: transmembrane; Zn: zinc; Fe: iron; Mn: manganese; Cu: copper.

\section{Authors' contributions}

$X Z$ and $X L$ initiated the project. XZ designed the experiment. XZ and LC carried out the experiments and analyzed the data. All authors wrote and revised the manuscript. All authors read and approved the final mansucript.

\section{Author details}

${ }^{1}$ Key Laboratory for Agricultural Water Resources, Center for Agricultural Resources Research, Institute of Genetics and Developmental Biology, Chinese Academy of Sciences, Shijiazhuang 050021, Hebei, People's Republic of China. ${ }^{2}$ CMLR, Sustainable Minerals Institute, The University of Queensland, Brisbane, QLD 4072, Australia.

\section{Acknowledgements}

Not applicable.

\section{Competing interests}

The authors declare that they have no competing interests.

\section{Availability of data and materials} Not applicable.

\section{Consent for publication}

Authors agree to the terms of the Springer Open Copyright and License Agreement.

\section{Ethics approval and consent to participate} Not applicable.

\section{Funding}

This work was supported by the Pioneer "Hundred Talents Program" of the Chinese Academy of Sciences (Y726012203), the National Key Research and Development Plan (2018YFD0800306) and the Hebei Science Fund for Distinguished Young Scholars (D2018503005).

\section{Publisher's Note}

Springer Nature remains neutral with regard to jurisdictional claims in published maps and institutional affiliations.

Received: 9 May 2018 Accepted: 17 September 2018

Published online: 25 September 2018 


\section{References}

Barberon M, Dubeaux G, Kolb C, Isono E, Zelazny E, Vert G (2014) Polarization of iron-regulated transporter 1 (IRT1) to the plant-soil interface plays crucial role in metal homeostasis. Proc Natl Acad Sci USA 111(22):8293-8298. https://doi.org/10.1073/pnas.1402262111

Blum A, Brumbarova T, Bauer P, Ivanov R (2014) Hormone influence on the spatial regulation of IRT1 expression in iron-deficient Arabidopsis thaliana roots. Plant Signal Behav 9(4):e28787

Bughio N, Yamaguchi H, Nishizawa NK, Nakanishi H, Mori S (2002) Cloning an iron-regulated metal transporter from rice. J Exp Bot 53(374):1677-1682

Chen WR, Feng Y, Chao YE (2008) Genomic analysis and expression pattern of OsZIP1, OsZIP3, and OsZIP4 in two rice (Oryza sativa L.) genotypes with different zinc efficiency. Russ J Plant Physl+ 55(3):400-409. https ://doi.org/10.1134/s1021443708030175

Connolly EL, Fett JP, Guerinot ML (2002) Expression of the IRT1 metal transporter is controlled by metals at the levels of transcript and protein accumulation. Plant Cell 14(6):1347-1357

Eide D, Broderius M, Fett J, Guerinot ML (1996) A novel iron-regulated metal transporter from plants identified by functional expression in yeast. Proc Natl Acad Sci USA 93(11):5624-5628

Eng BH, Guerinot ML, Eide D, Saier MH Jr (1998) Sequence analyses and phylogenetic characterization of the ZIP family of metal ion transport proteins. J Membr Biol 166(1):1-7

Fan SK, Fang XZ, Guan MY, Ye YQ, Lin XY, Du ST, Jin CW (2014) Exogenous abscisic acid application decreases cadmium accumulation in Arabidopsis plants, which is associated with the inhibition of IRT1-mediated cadmium uptake. Front Plant Sci 5:721. https://doi.org/10.3389/ fpls.2014.00721

Grotz N, Fox T, Connolly E, Park W, Guerinot ML, Eide D (1998) Identification of a family of zinc transporter genes from Arabidopsis that respond to zinc deficiency. Proc Natl Acad Sci USA 95(12):7220-7224

Guerinot ML (2000) The ZIP family of metal transporters. Biochim Biophys Acta 1465(1-2):190-198

Hammes UZ, Schachtman DP, Berg RH, Nielsen E, Koch W, McIntyre LM, Taylor CG (2005) Nematode-induced changes of transporter gene expression in Arabidopsis roots. Mol Plant Microbe Interact 18(12):1247-1257. https:// doi.org/10.1094/MPMI-18-1247

Henriques R, Jasik J, Klein M, Martinoia E, Feller U, Schell J, Pais MS, Koncz C (2002) Knock-out of Arabidopsis metal transporter gene IRT1 results in iron deficiency accompanied by cell differentiation defects. Plant Mol Biol 50(4-5):587-597

Inaba S, Kurata R, Kobayashi M, Yamagishi Y, Mori I, Ogata Y, Fukao Y (2015) Identification of putative target genes of bZIP19, a transcription factor essential for Arabidopsis adaptation to Zn deficiency in roots. Plant J 84(2):323-334. https://doi.org/10.1111/tpj.12996

Ishimaru Y, Suzuki M, Kobayashi T, Takahashi M, Nakanishi H, Mori S, Nishizawa NK (2005) OsZIP4, a novel zinc-regulated zinc transporter in rice. J Exp Bot 56(422):3207-3214. https://doi.org/10.1093/jxb/eri317

Ishimaru Y, Suzuki M, Tsukamoto T, Suzuki K, Nakazono M, Kobayashi T, Wada Y, Watanabe S, Matsuhashi S, Takahashi M, Nakanishi H, Mori S, Nishizawa NK (2006) Rice plants take up iron as an $\mathrm{Fe}^{3+}$-phytosiderophore and as Fe ${ }^{2+}$. Plant J 45(3):335-346. https://doi.org/10.1111/j.1365$313 \times .2005 .02624 . x$

Ivanov R, Bauer P (2017) Sequence and coexpression analysis of iron-regulated ZIP transporter genes reveals crossing points between iron acquisition strategies in green algae and land plants. Plant Soil 418(1-2):61-73. https ://doi.org/10.1007/s11104-016-3128-2

Kavitha PG, Kuruvilla S, Mathew MK (2015) Functional characterization of a transition metal ion transporter, OsZIP6 from rice (Oryza sativa L.). Plant Physiol Biochem 97:165-174. https://doi.org/10.1016/j.plaph y.2015.10.005

Korshunova YO, Eide D, Clark WG, Guerinot ML, Pakrasi HB (1999) The IRT1 protein from Arabidopsis thaliana is a metal transporter with a broad substrate range. Plant Mol Biol 40(1):37-44

Kumar S, Stecher G, Tamura K (2016) MEGA7: molecular evolutionary genetics analysis version 7.0 for bigger datasets. Mol Biol Evol 33(7):1870-1874. https://doi.org/10.1093/molbev/msw054

Lee $S, A n G$ (2009) Over-expression of OsIRT1 leads to increased iron and zinc accumulations in rice. Plant Cell Environ 32(4):408-416. https://doi.org/10 $.1111 / j .1365-3040.2009 .01935 . x$
Lee S, Jeong HJ, Kim SA, Lee J, Guerinot ML, An G (2010a) OsZIP5 is a plasma membrane zinc transporter in rice. Plant Mol Biol 73(4-5):507-517. https ://doi.org/10.1007/s11103-010-9637-0

Lee S, Kim SA, Lee J, Guerinot ML, An G (2010b) Zinc deficiency-inducible OsZIP8 encodes a plasma membrane-localized zinc transporter in rice. Mol Cells 29(6):551-558. https://doi.org/10.1007/s10059-010-0069-0

Li S, Zhou X, Huang Y, Zhu L, Zhang S, Zhao Y, Guo J, Chen J, Chen R (2013) Identification and characterization of the zinc-regulated transporters, iron-regulated transporter-like protein (ZIP) gene family in maize. BMC Plant Biol 13:114. https://doi.org/10.1186/1471-2229-13-114

Lin YF, Liang HM, Yang SY, Boch A, Clemens S, Chen CC, Wu JF, Huang JL, Yeh KC (2009) Arabidopsis IRT3 is a zinc-regulated and plasma membrane localized zinc/iron transporter. New Phytol 182(2):392-404. https://doi. org/10.1111/j.1469-8137.2009.02766.x

Livak KJ, Schmittgen TD (2001) Analysis of relative gene expression data using real-time quantitative PCR and the 2(-Delta Delta C(T)) Method. Methods 25(4):402-408. https://doi.org/10.1006/meth.2001.1262

Lopez-Millan AF, Ellis DR, Grusak MA (2004) Identification and characterization of several new members of the ZIP family of metal ion transporters in Medicago truncatula. Plant Mol Biol 54(4):583-596. https://doi. org/10.1023/B:PLAN.0000038271.96019.aa

Milner MJ, Seamon J, Craft E, Kochian LV (2013) Transport properties of members of the ZIP family in plants and their role in $\mathrm{Zn}$ and $\mathrm{Mn}$ homeostasis. J Exp Bot 64(1):369-381. https://doi.org/10.1093/jxb/ers315

Nakanishi H, Ogawa I, Ishimaru Y, Mori S, Nishizawa NK (2006) Iron deficiency enhances cadmium uptake and translocation mediated by the $\mathrm{Fe}^{2+}$ transporters OsIRT1 and OsIRT2 in rice. Soil Sci Plant Nutr 52(4):464-469. https://doi.org/10.1111/j.1747-0765.2006.00055.x

Nishida S, Tsuzuki C, Kato A, Aisu A, Yoshida J, Mizuno T (2011) AtIRT1, the primary iron uptake transporter in the root, mediates excess nickel accumulation in Arabidopsis thaliana. Plant Cell Physiol 52(8):1433-1442. https ://doi.org/10.1093/pcp/pcr089

Potocki S, Valensin D, Camponeschi F, Kozlowski H (2013) The extracellular loop of IRT1 ZIP protein-the chosen one for zinc? J Inorg Biochem 127:246-252. https://doi.org/10.1016/j.jinorgbio.2013.05.003

Rafiq MT, Aziz R, Yang XE, Xiao WD, Rafiq MK, Ali B, Li TQ (2014) Cadmium phytoavailability to rice (Oryza sativa L.) grown in representative Chinese soils. A model to improve soil environmental quality guidelines for food safety. Ecotox Environ Safe 103:101-107. https://doi.org/10.1016/j.ecoen v.2013.10.016

Ramesh SA, Shin R, Eide DJ, Schachtman DP (2003) Differential metal selectivity and gene expression of two zinc transporters from rice. Plant Physiol 133(1):126-134

Rogers EE, Eide DJ, Guerinot ML (2000) Altered selectivity in an Arabidopsis metal transporter. Proc Natl Acad Sci USA 97(22):12356-12360. https:// doi.org/10.1073/pnas.210214197

Shanmugam V, Lo JC, Wu CL, Wang SL, Lai CC, Connolly EL, Huang JL, Yeh KC (2011) Differential expression and regulation of iron-regulated metal transporters in Arabidopsis halleri and Arabidopsis thaliana-the role in zinc tolerance. New Phytol 190(1):125-137. https://doi.org/10.111 1/j.1469-8137.2010.03606.x

Shin LJ, Lo JC, Chen GH, Callis J, Fu H, Yeh KC (2013) IRT1 degradation factor1, a ring $\mathrm{E} 3$ ubiquitin ligase, regulates the degradation of iron-regulated transporter 1 in Arabidopsis. Plant Cell 25(8):3039-3051. https://doi. org/10.1105/tpc.113.115212

Stephens BW, Cook DR, Grusak MA (2011) Characterization of zinc transport by divalent metal transporters of the ZIP family from the model legume Medicago truncatula. Biometals 24(1):51-58. https://doi.org/10.1007/ s10534-010-9373-6

Talke IN, Hanikenne M, Kramer U (2006) Zinc-dependent global transcriptional control, transcriptional deregulation, and higher gene copy number for genes in metal homeostasis of the hyperaccumulator Arabidopsis halleri. Plant Physiol 142(1):148-167. https://doi.org/10.1104/pp.105.076232

Tiong J, McDonald G, Genc Y, Shirley N, Langridge P, Huang CY (2015) Increased expression of six ZIP family genes by zinc ( $Z n)$ deficiency is associated with enhanced uptake and root-to-shoot translocation of Zn in barley (Hordeum vulgare). New Phytol 207(4):1097-1109. https://doi. org/10.1111/nph.13413

Varotto C, Maiwald D, Pesaresi P, Jahns P, Salamini F, Leister D (2002) The metal ion transporter IRT1 is necessary for iron homeostasis and efficient photosynthesis in Arabidopsis thaliana. Plant J 31(5):589-599 
Vert G, Briat JF, Curie C (2001) Arabidopsis IRT2 gene encodes a root-periphery iron transporter. Plant J 26(2):181-189

Vert G, Grotz N, Dedaldechamp F, Gaymard F, Guerinot ML, Briat JF, Curie C (2002) IRT1, an Arabidopsis transporter essential for iron uptake from the soil and for plant growth. Plant Cell 14(6):1223-1233

Vert G, Barberon M, Zelazny E, Seguela M, Briat JF, Curie C (2009) Arabidopsis IRT2 cooperates with the high-affinity iron uptake system to maintain iron homeostasis in root epidermal cells. Planta 229(6):1171-1179. https ://doi.org/10.1007/s00425-009-0904-8
Wintz H, Fox T, Wu YY, Feng V, Chen W, Chang HS, Zhu T, Vulpe C (2003) Expression profiles of Arabidopsis thaliana in mineral deficiencies reveal novel transporters involved in metal homeostasis. J Biol Chem 278(48):4764447653. https://doi.org/10.1074/jbc.M309338200

Yang X, Huang J, Jiang Y, Zhang HS (2009) Cloning and functional identification of two members of the ZIP (Zrt, Irt-like protein) gene family in rice (Oryza sativa L.). Mol Biol Rep 36(2):281-287. https://doi.org/10.1007/ s11033-007-9177-0

\section{Submit your manuscript to a SpringerOpen ${ }^{\circ}$ journal and benefit from:}

- Convenient online submission

- Rigorous peer review

- Open access: articles freely available online

- High visibility within the field

- Retaining the copyright to your article

Submit your next manuscript at $\boldsymbol{\nabla}$ springeropen.com 